\title{
Tuberculosis: Awareness among Students in a Saudi University
}

\author{
Sultan B. AlSalem1*, Abdullah M. AlEisa1, Ismail A. Raslan1, Abdulrahman S. BinJawhar1, \\ Abdalla F. Khouqeer ${ }^{1}$, Ashry Gad ${ }^{2}$ \\ ${ }^{1}$ King Khalid University Hospital, College of Medicine, King Saud University, Riyadh, KSA \\ ${ }^{2}$ Department of Family and Community Medicine, College of Medicine, King Saud University, Riyadh, KSA \\ Email: * Sultanbalsalem@gmail.com
}

Received 3 January 2015; accepted 31 January 2015; published 4 February 2015

Copyright (C) 2015 by authors and Scientific Research Publishing Inc.

This work is licensed under the Creative Commons Attribution International License (CC BY). http://creativecommons.org/licenses/by/4.0/

(c) (i) Open Access

\begin{abstract}
Background: Knowledge plays a vital role in influencing the behavior and practices of individuals. Tuberculosis (TB) is a major public health problem. Our objective is to identify the extent of awareness about TB among King Saud University students, and to compare knowledge about tuberculosis amongst different University tracks. Methods: This study was conducted using a crosssectional approach including 530 students in three different academic tracks: Health, Scientific, and Humanitarian tracks. For data collection, a structured questionnaire was developed through revision of the literature which contained three different parts; demographic data of subjects, knowledge about TB and attitude toward TB. Results: The established scoring system revealed a poor grade of knowledge at $\mathbf{5 1 . 4 \%}$. Tuberculosis knowledge was significantly higher amongst the track of Health colleges $(46.7 \%$ compared with $27.2 \%$ for the track of Science and $26 \%$ for the track of Humanitarian studies). However, some of the issues were answered fittingly in higher magnitude by the two other non-health tracks; there was no significant difference in gender-specific awareness level (48\% for both). Conclusion: Although the Health track has better knowledge in general (46.7\%), the level of awareness of Tuberculosis is poor among King Saud University students. Moreover, the level of awareness differs among the three tracks, which are health, humanitarian, and science. The health track showed the highest level of awareness.
\end{abstract}

\section{Keywords}

Tuberculosis, King-Saud-University Students, Awareness, Knowledge, Attitude

\section{Introduction}

Tuberculosis (TB) is a major public health concern in Saudi Arabia [1]. It is caused by various strains of myco-

${ }^{*}$ Corresponding author. 
bacteria, usually Mycobacterium tuberculosis [2]. It has re-emerged as a community health problem in the 1980's, worldwide. It has been estimated by the World Health Organization (WHO), that about 5000 people die of the disease and 20,000 are becoming infected each day [3]. The incidence rate (per 100,000 populations) has been decreasing by $1.3 \%$ per year since 2002. Since the year 2006, the prevalence of TB cases per year has been falling. If these trends continue, the incidence will be falling and the target of the MDG will be reached by 2015. Even though the prevalence of tuberculosis is decreasing worldwide, it is doubtful to reach a $50 \%$ reduction of tuberculosis compared with 1990 as Stop TB partnership estimated [4]. In Saudi Arabia, the total number of reported tuberculosis cases in the year 2008 was 3918 cases in a population of approximately 24,807,273 individuals' [4]. It affects mainly young and middle-aged individuals; most of them aged between 15 and 44 years old. The incidence of all cases was estimated at 15.8 for every 100,000, and the estimated prevalence of all forms of TB cases was 65/100,000 population/year [4]. Public awareness is essential for the reduction of both mortality and morbidity of TB [5]. It is well established that good public awareness correlates well with the early detection of disease. Knowledge plays a vital role in influencing the behavior and practices of the individuals. Early detection and diagnosis of TB can cause a decrease in TB mortalities and occurrence [6]. TB is a disease, which is stigmatized by the community leading to social rejection [7]-[9].

Literature review does not reveal previous studies assessing tuberculosis public awareness conducted in Saudi Arabia. Therefore, the objective of this study is to assess the extent of awareness amongst King Saud University students regarding TB.

\section{Materials and Methods}

\subsection{Study Design and Sample Size}

This study was conducted using a cross-sectional approach targeting students from King Saud University (KSU) including different academic tracks: Health, Scientific, and Humanitarian tracks. Sample size was determined assuming the prevalence of poor knowledge of TB equals $30 \%$ and degree of precision $=0.05$. A stratified random sampling technique was used to recruit the respondents. To compensate for non-responders, $32 \%$ were added, which yielded a total sample of 530. The stratification was done according to the tracks and colleges. Proportionate allocation method was used to determine the number of participants from each college. Ethical approval of the study protocol was obtained from college of medicine ethical committee (IRB). Letter of study approval from the college of medicine was sent to track administrators

\subsection{Sampling and Data Collection}

For data collection, a structured self-administered questionnaire was developed through revision of the literature it contained three different parts; demographic data of subjects, e.g. demographic variables; gender, and age; knowledge about TB and attitude toward TB*. The questionnaire was tested for validity and reliability. The participants completed the questionnaires through self-administration. Questionnaires were distributed according to the number of students of the three-abovementioned tracks. The health track included colleges of medicine, dentistry, and pharmacy, College of science, college of business and administration, college of engineering and college of computer and information sciences within the track of science colleges, college of law and political sciences, college of languages, college of education and college of literature within the track of humanitarian colleges. TB-specific variables e.g. etiology, mode of spread, contagiousness, signs and symptoms, etc, known TB patients will be excluded from the study. SPSS software was used in data tabulations and analysis [10]. Quantitative continuous variables were compared using independent t-tests. Chi-square/Fisher's exact test was used for categorical variables. A score of awareness level was made and implemented on two stages. In the first stage, data for assessing knowledge were scored as " 1 " for correct answers and " 0 " for false ones. In the second stage, the total score were classified into two separate groups' i.e. poor and good knowledge. Median was used as a threshold for grading knowledge of Tuberculosis. The group of good knowledge resembled participants who scored the median and above. On the other hand, those who scored less than the median were considered the poor knowledge group.

\section{Results}

\subsection{Demographic Data}

Five hundred thirty questionnaires were distributed to King Saud University students; 499 completed the ques- 
tionnaires (94\%), 347 (69.5\%) males and 152 (30.5\%) females. The sample included the three tracks: Colleges of Health, Colleges of Science, and Humanitarian colleges (21.2\%, 24.4\%, and 53.7\%, respectively.) The mean age of participants was $21.54 \pm 2.06$ years. Smokers were $14.2 \%$, and the ex-smokers were $3.4 \%$ (Table 1). $83.4 \%$ of the participants have heard about tuberculosis. The sources of the knowledge were by television (37.1\%), internet (29.5\%), newspaper (21.6\%), health brochures (24.4\%), a family member (19.0\%), and friends (15.8\%) (Table 2).

Table 1. Demographic characteristics of King Saud University students who participated in the study.

\begin{tabular}{|c|c|c|}
\hline Characteristics & Frequency & Percent \\
\hline \multicolumn{3}{|l|}{ 1-Gender } \\
\hline Male & 347 & 69.5 \\
\hline Female & 152 & 30.5 \\
\hline Total & 499 & $100 \%$ \\
\hline 2-Age $\overline{\mathbf{x}} \pm$ SD & $21.544 \pm 1.058$ & \\
\hline \multicolumn{3}{|l|}{ 3-Marital status } \\
\hline Single & 461 & 93 \\
\hline Married & 34 & 6.8 \\
\hline Divorced & 1 & 0.2 \\
\hline Total & 496 & $100 \%$ \\
\hline \multicolumn{3}{|l|}{ 4-Tracks } \\
\hline Science colleges & 122 & 24.6 \\
\hline Health colleges & 106 & 21.4 \\
\hline Humanitarian colleges & 268 & 54 \\
\hline Total & 496 & $100 \%$ \\
\hline \multicolumn{3}{|l|}{ 5-Residence } \\
\hline Riyadh & 487 & 98.5 \\
\hline Outside Riyadh & 7 & 1.5 \\
\hline Total & 494 & $100 \%$ \\
\hline 6-GPA $\overline{\mathbf{x}} \pm$ SD & $3.72 \pm 0.75$ & \\
\hline \multicolumn{3}{|c|}{ 7-Mothers' educational level } \\
\hline Less than secondary & 134 & 30.2 \\
\hline Secondary & 112 & 25.2 \\
\hline University & 181 & 40.8 \\
\hline Post-graduate & 17 & 3.8 \\
\hline Total & 444 & $100 \%$ \\
\hline \multicolumn{3}{|c|}{ 8-Fathers' educational leved } \\
\hline Less than secondary & 70 & 16 \\
\hline Secondary & 97 & 22 \\
\hline University & 209 & 47 \\
\hline Post-graduate & 68 & 15 \\
\hline Total & 444 & $100 \%$ \\
\hline
\end{tabular}

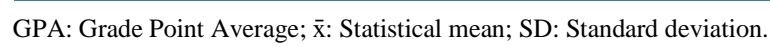


Table 2. Source of knowledge about tuberculosis among KSU students.

\begin{tabular}{ccc}
\hline \multirow{2}{*}{ Source of knowledge } & Table column head \\
\cline { 2 - 3 } Television & Frequency & Percent \\
Internet & 185 & 37.1 \\
Health brochures & 147 & 29.5 \\
Newspaper & 122 & 24.4 \\
Family member & 108 & 21.6 \\
Friends & 95 & 19.0 \\
Others & 79 & 15.8 \\
\hline
\end{tabular}

\subsection{Knowledge about Tuberculosis (TB)}

The proportion of participants who know someone that has been infected with TB was 14.0\%. Around 63.0\% recorded that tuberculosis was infectious, while only 5.0\% thought TB is hereditary. About 68.1\% of participants have chosen lungs as the most commonly affected organ by tuberculosis. Other organs that may be infected as liver, kidney, bone, spine, testicles, brain, and ears were 19.2\%, 14.4\%, 10.8\%, 8.8\%, 8.2\%, 6, 8\%, and $2.2 \%$, respectively.

Around half of the participants have picked virus as the cause of tuberculosis (46.3\%), however $44.3 \%$ of them concomitantly selected bacteria. Reported methods of TB spread were cough-air (57\%), unclean food or water (19\%), sexual contact with TB patient (18.6\%), public areas (11.6\%), hereditary (6.6\%), whereas (20.6\%) did not know. Most participants (69.3\%) have selected immuno-compromise as a risk-factor for developing Tuberculosis. Followed by, overcrowding (30.9\%), smoking (27.7\%), illegal drug use (14.2\%), genetic predisposition (11.8\%), and alcohol (8.6\%) (Table 3).

A total of 335 participants (67.1\%) considered TB is a preventable disease. Regarding method of the prevention, $79.7 \%$ of them believe that TB is prevented primarily by vaccination, and $20.3 \%$ of the participants reported that TB could be prevented by other methods.

Regarding Symptoms of TB, (47.9\%) of the participants considered coughing blood as a symptom of TB, (44.9\%) agreed that productive/prolonged cough is a symptom of TB. In addition, other symptoms reported, include constipation (37\%), night sweating (22\%) and weight loss (3.6\%). Symptoms such as chest pain, fever, pallor, appetite loss, diarrhea, itching, and impotence were agreed upon being symptoms of TB by 35.7\%, 31.5\%, $30.3 \%$, 22\%, $16 \%, 14 \%$, and $5.2 \%$, respectively.

As regards to the duration of treatment of TB, 295 participants (59\%) did not know the duration of TB treatment. 90 participants (18\%) answered with 6 - 9 months, and 63 (12.6\%) chose 1 - 5 months as the duration of treatment.

For side effects of TB treatment, 218 (43.7\%) participants do not know side effects of treatment. 123 participants reported jaundice (24.6\%) while Dizziness was reported by (23.6\%). 71 participants (14.2\%) responded that red-orange urine was a possible side effect (Table 4).

Concerning the complications of TB, 197 (39.5\%) reported that death is a complication of TB. 189 (37.9\%) chose relapse. Furthermore, 175 participants (35.1\%) believed that generalized TB was a complication of TB. Drug resistance, bleeding, and cancer were reported by $16.8 \%, 22.8 \%$, and $4.2 \%$, respectively.

\subsection{Score Grading System}

Grade of knowledge in students of King Saud University, according to the median, 179 (51.4\%) participants have poor knowledge and 169 (48.6\%) have good knowledge. The maximum score was 19 out of 21 , and the minimum was one. The mean was $9.54 \pm 3.93$ and a median was 9.0.

Table 5 showed that approximately half of all participants of both genders had poor grade of knowledge. The mean age of people who had poor knowledge was $21.56 \pm 2.01$ years. While the mean age of participants with good knowledge was $21.44 \pm 1.82$ years with no statistical significance $(\mathrm{P}=0.284)$, in-between $51.4 \%$ of participants achieved poor grade of knowledge, with $90 \%$ of them being single, which is not statistically significant 
Table 3. Perception of King Saud University students regarding risk factors of tuberculosis.

\begin{tabular}{ccc}
\hline \multirow{2}{*}{ Risk factor } & \multicolumn{2}{c}{ Table column head } \\
\cline { 2 - 3 } & Frequency & Percent \\
\hline Smoking & 138 & 27.7 \\
Overcrowding & 154 & 30.9 \\
Genetic predisposition & 59 & 11.8 \\
Immuno-compromised & 346 & 69.3 \\
Alcohol & 43 & 8.6 \\
Illegal drug use & 71 & 14.2 \\
\hline
\end{tabular}

Table 4. Awareness of KSU students regarding duration and side effects of TB treatment.

\begin{tabular}{ccc}
\hline \multirow{2}{*}{ Treatment characteristic } & Table column head & Percent \\
\cline { 2 - 3 } Duration & Frequency & \\
$1-5$ months & 63 & 12.9 \\
6 - 9 months & 90 & 18.4 \\
10 - 12 months & 39 & 8.0 \\
Don't know & 295 & 60.5 \\
Total & 487 & $100 \%$ \\
Side effect & & \\
Jaundice & 123 & 24.6 \\
Dizziness & 118 & 23.6 \\
Red-orange urine & 71 & 14.2 \\
Vomiting & 89 & 17.8 \\
Muscle/joint pain & 62 & 12.4 \\
Itching & 40 & 8.0 \\
Diarrhea & 41 & 8.2 \\
Don't know & 218 & 43.7 \\
\hline
\end{tabular}

$(\mathrm{P}=0.062)$.

Regarding the grade of knowledge in the different colleges of King Saud University, 9.2\% of the participants in Health Colleges had a poor knowledge. In contrast, $47.12 \%$ and $74.5 \%$ of the participants in Scientific Colleges and Humanitarian Colleges, respectively, had a poor knowledge with statistical significance in-between (P < 0.05). Considering the maternal level of education, $8.4 \%$ of the participants whom mothers had a post-graduate degree had poor knowledge, while $45.5 \%$ with a mother's education of a graduate degree had a poor knowledge. As regards the father's education and grade of knowledge, $28 \%$ of participants with father's post-graduate degree had a poor knowledge. 41.5\% with father's pre-high-school degree had a poor knowledge. 50.4\% with father's graduate degree had a poor knowledge. $62.4 \%$ of the participants with father's high school degree had a poor knowledge, which is statistically significant $(\mathrm{P}<0.05)$. As for smokers, $52.9 \%$ of the smokers had a poor knowledge. While $51.2 \%$ of the non-smokers had a poor knowledge and $44.4 \%$ of the ex. Smokers had poor knowledge, this was not statistically significant $(\mathrm{P}=0.894)$.

\section{Discussion}

\subsection{Social Demographic Characteristics}

Tuberculosis remains the second most common cause of death due infectious diseases after HIV/AIDS. It con- 
Table 5. Demographic characteristics and grade of knowledge in KSU students.

\begin{tabular}{|c|c|c|c|c|}
\hline \multirow{2}{*}{ Characteristics } & \multicolumn{4}{|c|}{ Grade of knowledge } \\
\hline & Poor n (\%) & Good n (\%) & Total & $\mathrm{P}$ \\
\hline \multicolumn{5}{|l|}{ 1-Gender (398) } \\
\hline Male & $121(67.5)$ & $114(67.4)$ & 235 & \multirow[t]{2}{*}{0.90} \\
\hline Female & $58(32.4)$ & $55(32.5)$ & 113 & \\
\hline 2-Age $\overline{\mathbf{x}} \pm$ SD & $21.56 \pm 2.08$ & $21.44 \pm 1.81$ & $21.50 \pm 1.95$ & 0.28 \\
\hline \multicolumn{5}{|l|}{ 3-Marital status (346) } \\
\hline Single & $160(89.8)$ & $160(95.2)$ & 320 & \multirow{3}{*}{0.62} \\
\hline Married & $18(10.1)$ & $7(4.1)$ & 25 & \\
\hline Divorced & 0 & $1(0.05)$ & 1 & \\
\hline \multicolumn{5}{|l|}{ 4-Tracks (347) } \\
\hline Science colleges & $41(23)$ & $46(27.2)$ & 87 & \multirow{3}{*}{$<0.001$} \\
\hline Health colleges & $8(4.4)$ & 79 (46.7) & 87 & \\
\hline Humanitarian colleges & $129(72.4)$ & $44(26)$ & 173 & \\
\hline 5-GPA $\overline{\mathbf{x}} \pm$ SD & $3.61 \pm 0.72$ & $3.98 \pm 0.71$ & $3.79 \pm 0.74$ & 0.108 \\
\hline \multicolumn{5}{|c|}{ 6-Mothers' educational level } \\
\hline Less than secondary & $45(30.2)$ & $37(24.1)$ & 82 & \\
\hline Secondary & $43(28.8)$ & $33(21.5)$ & 76 & \multirow{3}{*}{0.009} \\
\hline University & $60(40.2)$ & $72(47)$ & 132 & \\
\hline Post-graduate & $1(0.6)$ & $11(7.1)$ & 12 & \\
\hline \multicolumn{5}{|c|}{ 7-Fathers' educational level } \\
\hline Less than secondary & 17 (11.5) & $24(15.1)$ & 41 & \multirow{4}{*}{0.002} \\
\hline Secondary & $43(29.2)$ & $26(16.4)$ & 69 & \\
\hline University & $73(49.6)$ & $72(45.5)$ & 145 & \\
\hline Post-graduate & $14(9.5)$ & $36(22.7)$ & 50 & \\
\hline \multicolumn{5}{|l|}{ 8-Smoking status (345) } \\
\hline Yes & $27(15.2)$ & $24(14.2)$ & 51 & \multirow{3}{*}{0.894} \\
\hline No & $146(82.4)$ & 139 (82.7) & 285 & \\
\hline Ex. smoker & $4(2.2)$ & $5(2.9)$ & 9 & \\
\hline
\end{tabular}

stitutes a major burden on health care systems across the globe [11]. In the meanwhile, no major recent advancesin anti-TB drug development or research efforts showed any immediate meaningful reduction of Tuberculosis cases. Tuberculosis in Saudi Arabia affects mainly young and middle-aged individuals [4]. The World Health Organization has called for campaigns to increase awareness of TB [1] [12].

The current study's respondents with parents having secondary or higher education had significantly higher score on general knowledge on TB. This showed education was an important determinant of general knowledge on TB. The study is supported by other studies namely Westaway M.S [7] and Kim et al. [13].

As predicted, tuberculosis knowledge was significantly higher amongst the Health track colleges compared with the two other tracks. This can be explained by the fact that health colleges most probably have had studied 
TB at some point in their curriculum. This variability in knowledge about TB should point out the populations in which proper health measures are put into appropriate practice.

The current finding is consistent with other analogous studies worldwide [14]. In the present work, an implementation of a validated scoring system was made. This study compared men and women, and found, in general, that TB awareness level was similar. Similar findings were reported by other studies [8] [13] [15].

\subsection{Knowledge about Tuberculosis (TB)}

Current overseas studies on awareness of people regarding tuberculosis have revealed both similar and contrasting aspects of the awareness level. For example, regarding the nature of tuberculosis, one study in Rajasthan, India has revealed that only six (1.6\%) out of 376 participants knew that tuberculosis is caused by a germ, while 206 (54.8\%) had the misconception that tuberculosis is a hereditary disease [9]. In addition, a study conducted in Vietnam stated that 6071 (50\%) out of 12143 had the same misconception that tuberculosis is also a hereditary disease [16]. In contrast, our study showed that only 33 (6.6\%) out of 499 participant had the same misconception of tuberculosis being hereditary, while a larger proportion 383 (76.7\%) knew that it is spread through air and unclean food. This large dissimilarity can be linked to the different educational systems and the abundance of tuberculosis awareness programs held in the vicinity in addition to the high prevalence of TB in South East Asia and occurrence of more than one case within the family.

Concerning the symptoms of tuberculosis, A study that was conducted in Sabah, Malaysia revealed that 91 (46.2\%) and 73 (37.1\%) out of 197 knew that tuberculosis is associated with hemoptysis and cough, respectively [8]. Likewise, a study that was conducted in China where only 10453 (15.1\%) out of 69253 participants knew that prolonged cough is associated that tuberculosis [15]. Moreover, a study that was conducted in Rajasthan, India showed that 90 (23.9\%) out 376 participants knew chest pain is a symptom of tuberculosis [9]. However, in another worldwide internet survey with a sample size of 564, around $49 \%$ reported cough as the commonest symptom of TB [17]. Compared to our study, 239 (47.9\%) and 224 (44.9\%) out of 499 participants knew that cough with blood and prolonged cough without blood, respectively, are symptoms of tuberculosis. Around one third knew that chest pain is associated with tuberculosis. It is evident that the knowledge in our subjects is slightly higher than some other countries. This difference might be attributed to the stereotypical stigmatization about tuberculosis in Saudi Arabia. In addition, in comparison to the study in China, the large difference in knowledge might be because they included only cough as a symptom of TB [15].

A population wise difference is noted in the three studies of Rajasthan, India and Sabah, Malaysia, and China. The studies included similar age groups as ours, except for the added recruitment of younger $(<20)$ respondents in the China [15] and Rajasthan studies [9]. They included individuals in older age groups, the highest being aged 65 years old [8] [9] [15]. This can explain the slight unalike findings in this study.

While the great majority of the respondents thought that TB is treatable and can be cured by modern medicine, one-fifth of the respondents knew the correct duration for treatment of TB. This misconception about the treatment duration of TB in our study requires appropriate educational approaches.

\section{Conclusion}

This study concludes that the level of awareness of Tuberculosis is poor among King Saud University students. It differs in the three university tracks, which are health, humanitarian, and science. Furthermore, according to the used scale, in both male and female sections, the health track has shown the highest level of awareness and the second highest is the science track, and, the humanitarian track has the lowest level of awareness overall.

\section{Acknowledgements}

The authors acknowledge the efforts and work of all who helped throughout the study, especially Ibrahim Ali Alshiddi.

\section{References}

[1] WHO. Tuberculosis Country Profiles, Epidemiology and Strategy. https://extranet.who.int/sree/Reports?op=Replet\&name=/WHO HQ Reports/G2/PROD/EXT/TBCountryProfile\&ISO $\underline{2=S A \& o u t t y p e}=$ html 
[2] Kumar, V., Abbas, A.K., Fausto, N. and Mitchell, R.N. (2007) Robbins Basic Pathology. 8th Edition, Saunders Elsevier, Philadelphia, 516-522.

[3] Beaglhole, R., Irwin, A. and Prentice, T. (2004) The World Health Report: 2004: Changing History. WHO, Geneva, 96.

[4] Al Jahdali, H., Baharoon, S., Abba, A., Memish, Z., Alrajhi, A., Albarrak, A., Haddad, Q., Alhajjaj, M., Pai, M. and Menzies, D. (2010) Saudi Guidelines for Testing and Treatment of Latent Tuberculosis Infection. Annals of Saudi Medicine, 30, 38-49. http://dx.doi.org/10.4103/0256-4947.59373

[5] Gijs, E., Mario, C.R. and Dermot, M. (2004) Scale Up: Meeting Targets in Global Tuberculosis Control. The Lancet, 363, 814-819.

[6] Suárez, P.G., Watt, C.J., Alarcón, E., Portocarrero, J., Zavala, D., Canales, R., Luelmo, F., Espinal, M.A. and Dye, C. (2001) The Dynamics of Tuberculosis in Response to 10 Years of Intensive Control Effort in Peru. The Journal of Infectious Diseases, 184, 473-478. http://dx.doi.org/10.4103/0256-4947.59373

[7] Westaway, M.S. (1989) Knowledge, Beliefs and Feeling about Tuberculosis. Health Education Research, Theory \& Practice, 4, 205-211.

[8] Koay, T.K. (2004) Knowledge and Attitudes towards Tuberculosis. Medical Journal of Malaysia, 59, 502-511.

[9] Yadav, S.P., Mathur, M.L. and Dixit, A.K. (2006) Knowledge and Attitude towards Tuberculosis among Sandstone Quarry Workers in Desert Parts of Rajasthan. Indian Journal of Tuberculosis, 53, 187-195.

[10] (2009) Statistical Package for Social Sciences (for Personal Computers) (SPSS-PC). Version 18, SPSS Co., Chicago.

[11] Dolin, R., Mandell, G.L. and Bennett, J.E. (2010) Mycobacterium Tuberculosis. Mandell, Douglas, and Bennett's Principles and Practice of Infectious Diseases. 7th Edition, Churchill Livingstone/Elsevier, Philadelphia, Chapter 250.

[12] Broekmans, J.F., Migliori, G.B., Reider, H.L., Leesz, J., Ruutu, P., Loddenkemperf, R. and Raviglione, M.C. (2002) European Framework for Tuberculosis Control and Elimination in Countries with a Low Incidence. Recommendations of the World Health Organization (WHO), International Union against Tuberculosis and Lung Disease (IUATLD) and Royal Netherlands Tuberculosis Association (KNCV) Working Group. European Journal of Respiratory Diseases, 19, 765-775. http://dx.doi.org/10.1183/09031936.02.00261402

[13] Kim, S.C., Jin, B.W., Shimao, T. and Mori, T. (1985) Study on the Knowledge of Tuberculosis and Attitudes towards the Disease. Bulletin of the International Union against Tuberculosis, 60, 131-132.

[14] Al-Jabri, A.A., Dorvlo, A.S., Al-Rahbi, S., Al-Abriand, J. and Al-Adawi, S. (2006) Knowledge of Tuberculosis among Medical Professionals and University Students in Oman. Eastern Mediterranean Health Journal, 12, 509-521.

[15] Lu, S.H., Tian, B.C., Kang, X.P., Zhang, W., Meng, X.P., Zhang, J.B. and Lo, S.K. (2009) Public Awareness of Tuberculosis in China: A National Survey of 69253 Subjects. International Journal of Tuberculosis and Lung Disease, 13, 1493-1499.

[16] Hoa, N.P., Chuc, N.T. and Thorson, A. (2009) Knowledge, Attitudes, and Practices about Tuberculosis and Choice of Communication Channels in a Rural Community in Vietnam. Health Policy, 90, 8-12. http://dx.doi.org/10.1016/j.healthpol.2008.08.006

[17] Corless, J., Stockton, P., Myers, S. and Davies, P. (2002) A World-Wide Internet Survey of Public Knowledge about Tuberculosis. Respiratory Medicine, 96, 59-60. http://dx.doi.org/10.1053/rmed.2001.1205 
Scientific Research Publishing (SCIRP) is one of the largest Open Access journal publishers. It is currently publishing more than 200 open access, online, peer-reviewed journals covering a wide range of academic disciplines. SCIRP serves the worldwide academic communities and contributes to the progress and application of science with its publication.

Other selected journals from SCIRP are listed as below. Submit your manuscript to us via either submit@scirp.org or Online Submission Portal.
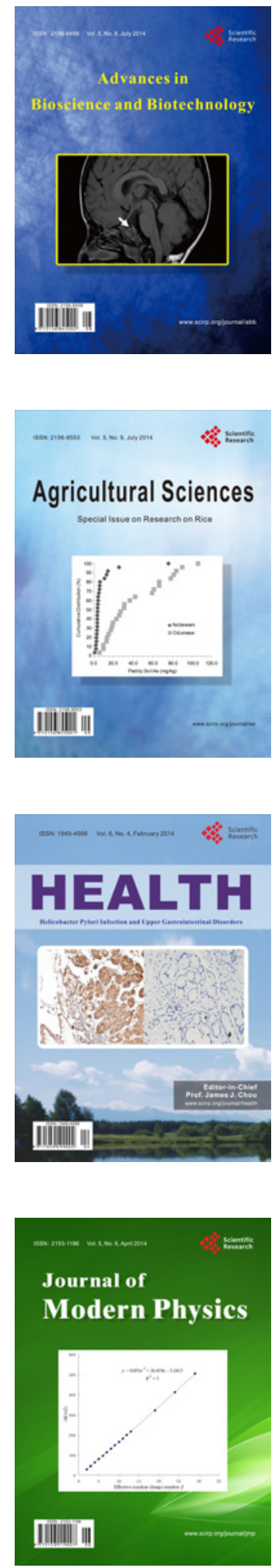
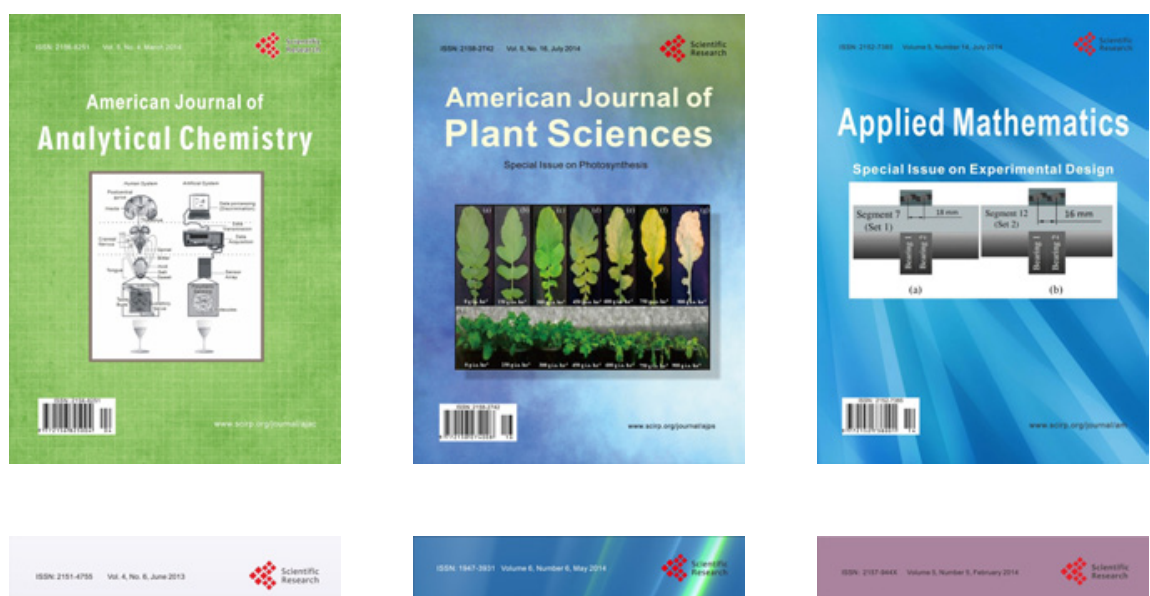

Creative Education
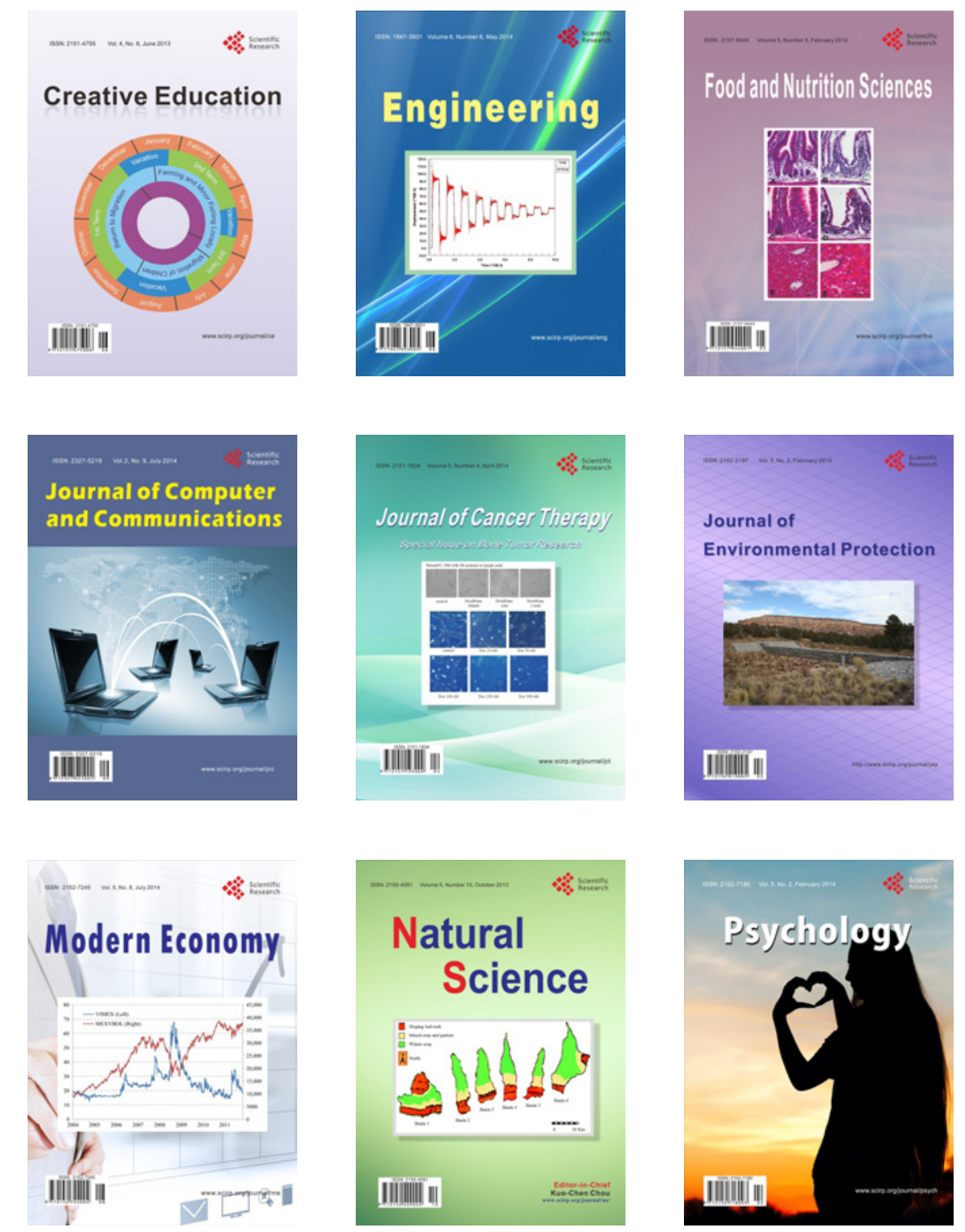